\title{
Sistem Pendukung Keputusan Pemilihan Kategori Promosi Produk Menggunakan Metode Profile Matching (Studi Kasus : Minimarket)
}

\author{
Yesni Malau \\ Universitas Bina Sarana Informatika, \\ E-mail : yesni.ymu@bsi.ac.id
}

\begin{abstract}
ABSTRAK
Perusahaan distributor secara berkala akan melakukan kegiatan promosi produk di beberapa outlet yang bekerjasama dengan mereka, kendala yang sering ditemui adalah pemberian promosi masih belum tepat sasaran sehingga belum bisa menarik minat pembeli, hal ini akan menjadikan tujuan utama perusahaan dalam mengadakan promosi guna meningkatkan volume dan omset penjualan masih belum sepenuhnya tercapai. Penelitian ini bertujuan memberikan solusi kepada perusahaan dalam mengambil keputusan pemilihan kategori promosi produk dengan menggunakan metode profile matching karena metode ini telah banyak digunakan dalam berbagai bidang untuk sistem pendukung keputusan. Pengambilan keputusan kategori promosi produk dilakukan dengan melihat tiga aspek yaitu budget, penjualan dan waktu promosi dengan pemberian bobot terhadap aspek yang telah ditentukan, perhitungan nilai core factor (NCF) dan nilai secondary factor (NSF), perhitungan nilai total akan menghasilkan rekomendasi kategori promosi produk. Ada empat kategori yang akan menjadi hasil rekomendasi untuk setiap promosi produk yaitu Rafaksi, Mailer, Discount dan Listing. Dengan dilakukannya penelitian ini akan membantu perusahaan distributor dalam menentukan promo untuk setiap produk yang dimiliki.
\end{abstract}

Kata Kunci: SPK, promosi produk, profile matching

\begin{abstract}
Distributor companies will periodically carry out product promotion activities in several outlets that collaborate with them, the obstacle that is often encountered is the promotion is still not on target so that it cannot attract buyers, this will make the company's main goal in conducting promotions in order to increase sales volume and turnover still not fully achieved. This study aims to provide solutions to companies in making decisions on the selection of product promotion categories using the profile matching method because the profile matching method has been widely used in various fields for decision support systems. Decision making of the product promotion category is done by looking at three aspects, namely budget, sales and time of promotion by giving weights to predetermined aspects, calculating the value of Core Factor (NCF) and the value of Secondary Factor (NSF), calculation of the total value will produce recommendations for the product promotion category. There are fours categories that will be the result of recommendations for each product promotion, namely Rafaksi, Mailer, Discount and Listing. By doing this research will help distributor companies determine the promos for each product they have.
\end{abstract}

Keyword:DSS, product promotion, profile matching

Author Korespondensi (Yesni Malau)

Email : yesni.ymu@bsi.ac.id

\section{PENDAHULUAN}

Secara berkala perusahaan selalu melakukan promosi di beberapa minimarket yang menjadi agen pemasarannya. Mengadakan promosi produk merupakan salah satu strategi yang dilakukan oleh perusahaan distributor untuk meningkatkan volume penjualan karena dengan tersedianya promosi akan lebih manarik minat konsumen dalam membeli produk, sehingga pemilihan strategi promosi yang tepat akan sangat membantu perusahaan distributor dalam mencapai tujuan yang ingin dicapai. 
Dalam mengadakan pemberian promosi produk, perusahaan memiliki beberapa kategori promosi yang dapat dipilih. Namun, dalam pelaksanaan-nya promosi produk tersebut masih belum bisa menarik minat pembeli dikarenakan berbagai hal tertentu, sehingga tujuan utama perusahaan dalam mengadakan promosi guna meningkatkan volume dan omzet penjualan masih belum sepenuhnya tercapai, hal inilah yang menjadi dasar pemikiran bahwa perusahaan membutuhkan sebuah sistem pendukung keputusan agar pemilihan kategori promosi produk tepat sasaran sehingga tujuan utama pengadaaan promosi tersebut dapat tercapai.

Sistem pendukung keputusan sangat membantu para pengambil keputusan dalam pemecahan masalah tanpa menggantikan peran penilaiannya. Sistem pendukung keputusan dapat diartikan sebagai suatu sistem interaktif berbasis komputer yang membantu para pengambil keputusan menyelesaikan masalah-masalah yang tidak terstruktur dengan memanfaatkan data dan model[1]. Memiliki banyak informasi saja tidak cukup, tetapi juga harus mampu meramunya dengan cepat menjadi alternatif terbaik di dalam proses pengambilan keputusan, pengambilan keputusan yang dilakukan secara cepat, tepat sasaran dan dapat dipertanggungjawabkan menjadi kunci keberhasilan dalam persaingan global di waktu mendatang.

Salah satu permasalahan dalam pengambilan keputusan yang dihadapkan pada berbagai kriteria adalah proses penentuan kebijakan strategi promosi sehingga dengan menentukan kebijakan strategi promosi yang tepat akan mendukung keberhasilan dari promosi tersebut dalam mengambil sebuah keputusan yang bijak[2]. Peran sebuah sistem pendukung keputusan dalam membantu menyelesaikan masalah-masalah yang tidak terstruktur telah banyak diterapkan, agar bisnis yang sedang dikelola bisa terus bertahan dan bersaing di bidangnya maka pengambilan keputusan terhadap sebuah promosi produk harus dilakukan tepat sasaran. Penerapan sistem pendukung keputusan dalam bisnis kuliner akan membantu dalam menentukan keputusan pemilihan produk promo secara tepat sesuai dengan kebutuhan dan kondisi yang ada guna membantu perusahaan agar tetap mampu bersaing, karena sebuah sistem pendukung keputusan mampu mem-bantu pihak restoran untuk memillih produk mana yang hendak diberikan promosi guna meningkatkan penjualan[3].

Selama ini pemilihan kategori promosi produk di minimarket dilakukan hanya berdasar-kan kebutuhan dan belum menggunakan metode sistem pengambilan keputusan sehingga pada saat kategori promosi produk diselenggarakan beberapa kegiatan promo belum sesuai dengan capaian target, sehingga penulis tertarik untuk menerapkan sistem pendukung keputusan pemilihan kategori promosi produk di minimarket dengan menggunakan metode profile matching. Metode profile matching telah banyak digunakan dalam berbagai bidang untuk sistem pendukung keputusan, dan diharapkan dengan penerapan metode ini dapat membantu pihak manajemen dalam pemilihan kategori promosi produk di minimarket.

\section{METODOLOGI}

Pada penelitian ini Penulis menggunakan metode profile matching dengan melihat aspek budget, penjualan dan waktu promosi untuk menentukan kategori promosi yang tepat untuk setiap produk promosi yang tersedia seperti rafaksi, mailer, discount dan listing. Metode profile matching ini merupakan salah satu metode yang dapat digunakan dalam sistem pendukung keputusan, karena secara umum digunakan untuk membandingkan kompetensi objek penelitian dengan kompetensi yang diharapkan, dimana selisih hasil perbandingan akan mendapatkan gap. Jika nilai gap semakin kecil maka terdapat peluang besar untuk nilai prioritas[4]. Beberapa tahapan yang penulis gunakan dalam penelitian pemilihan kategori promosi produk ini adalah :

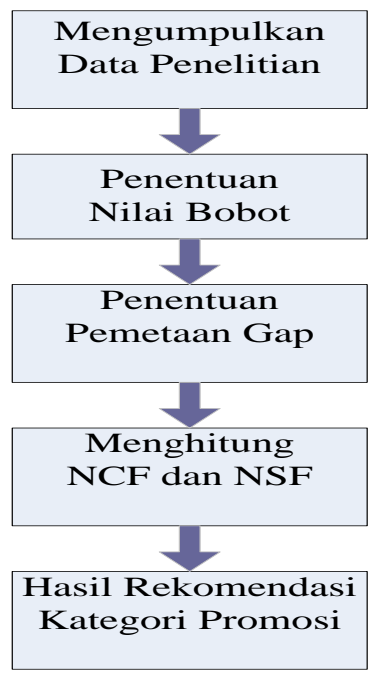

Gambar 1.Tahapan Penelitian 
a. Mengumpulkan data penelitian

Pengumpulan data pada tahap ini menggunakan metode kuantitatif deskriptif dengan mengambil data-data dari kategori promosi produk yang biasa digunakan di minimarket yaitu promosi rafaksi, mailer, discount dan listing dengan menghitung bobot berdasarkan aspek budget, penjualan dan waktu.

b. Penentuan nilai bobot

Pada tahap ini untuk setiap aspek budget, penjualan dan waktu akan dilakukan pemberian nilai bobot.

c. Penentuan pemetaan selisih atau gap

Tahap ini merupakan tahap pemetaan selisih atau gap dengan melakukan perhitungan pada masing-masing aspek pengelompokan selisih atau gap budget, penjualan dan waktu sesuai dengan tabel kriteria promosi. Setelah nilai akumulasi pemetaan masing-masing produk diketahui maka untuk menentukan selisih atau gap langkah selanjutnya adalah dengan mengurangi hasil pengelompokan selisih atau gap dengan kriteria tertinggi dari masingmasing aspek kategori promosi produk.

d. Menghitung NCF dan NSF

Pada tahap ini dilakukan perhitungan NCF dan NSF. Untuk nilai NCF didapat dari ratarata bobot nilai kategori promosi dan untuk Nilai NSF didapat dari bobot nilai secondary factor, dengan menggunakan rumus mencari NCF yaitu :

$$
N F C=\frac{\Sigma N C(a, n)}{\Sigma I C}
$$

Dimana:

$\mathrm{NCF}=$ Nilai rata-rata core factor

$\mathrm{NC}(\mathrm{a}, \mathrm{n})=$ Jumlah total nilai core factor (aspek promosi)

$\mathrm{IC}=$ Jumlah item core factor

Setelah mendapatkan nilai NCF dan NSF maka akan dilakukan perhitungan nilai total dengan rumus $70 \%$ NCF ditambah $30 \%$ NSF menggunakan rumus sebagai berikut [5]:

$N(a, n)=(x) \% N C F(a, n)+(x) \% N S F(a, n) . .(2)$

Dimana :

$\mathrm{N}(\mathrm{a}, \mathrm{n})=$ Total nilai aspek kategori promosi produk $(\mathrm{x}) \%=$ Nilai persen yang diinput

$\operatorname{NCF}(a, n)=$ Nilai rata-rata core factor

$\mathrm{NSF}(\mathrm{a}, \mathrm{n})=$ Nilai rata-rata secondary factor

e. Hasil Rekomendasi

Pada tahap ini akan dilakukan perbandingan untuk setiap nilai kategori promosi dan kategori nilai yang terbesar akan dijadikan sebagai hasil rekomendasi.

\section{HASIL DAN PEMBAHASAN}

\subsection{Mengumpulkan data penelitian}

Berdasarkan data kategori promosi produk yang selama ini sering digunakan di minimarket maka dilakukan pembobotan nilai untuk aspek budget (Tabel 1), penjualan (Tabel 2), dan waktu (Tabel 3).

Tabel 1. Aspek Budget

\begin{tabular}{|lc|}
\hline \multicolumn{1}{|c|}{ Budget } & Bobot \\
\hline 0-100 Juta & 4 \\
\hline$>$ 100 Juta dan $\leq 1$ Milyar & 3 \\
\hline$>$ 1 Milyar dan $\leq 5$ Milyar & 2 \\
\hline$>$ 5 Milyar & 1 \\
\hline
\end{tabular}

Tabel 2. Aspek Penjualan

\begin{tabular}{|llc|}
\hline & \multicolumn{1}{c}{ Penjualan } & Bobot \\
\hline$>$ 5 Milyar & 4 \\
\hline$>$ & 4 Milyar dan $\leq 5$ Milyar & 3 \\
\hline$>$ & 1 Milyar dan $\leq$ 4 Milyar & 2 \\
\hline$\leq$ 1 Milyar & 1 \\
\hline
\end{tabular}

Tabel 3. Aspek Waktu

\begin{tabular}{|lc|}
\hline \multicolumn{1}{|c|}{ Waktu } & Bobot \\
\hline 0-3 Hari & 5 \\
\hline 4-7 Hari & 4 \\
\hline 8-15 Hari & 3 \\
\hline 16-30 Hari & 2 \\
\hline$>30$ Hari & 1 \\
\hline
\end{tabular}

\subsection{Penentuan nilai bobot}

Selanjutnya untuk setiap aspek pada kategori promosi produk akan dilakukan pemberian nilai bobot untuk pengelompokan gap yaitu untuk aspek budget (B), penjualan (P) dan waktu (W) seperti terlihat pada tabel 4 . 
Tabel 4. Aspek untuk Pengelompokan Gap

\begin{tabular}{|llll|}
\hline \multicolumn{1}{|c}{ Nama Produk } & B & P & W \\
\hline Pengharum Ruangan Semprot & 3 & 2 & 4 \\
\hline $\begin{array}{l}\text { Pengharum Ruangan Kamar } \\
\text { Mandi }\end{array}$ & 4 & 2 & 4 \\
\hline $\begin{array}{l}\text { Pengharum Ruangan ALL in } \\
\text { One }\end{array}$ & 2 & 4 & 5 \\
\hline Obat Nyamuk Semprot & 4 & 4 & 4 \\
\hline Obat Nyamuk Non Stop & 3 & 1 & 5 \\
\hline Obat Nyamuk Anti Kecoa & 4 & 4 & 5 \\
\hline Tisu Basah Baby & 3 & 3 & 3 \\
\hline Tisu Basah Anti Septic & 2 & 4 & 5 \\
\hline Tisu Basah Reguler & 4 & 1 & 2 \\
\hline Pengharum Mobil Anti Bakteri & 4 & 3 & 5 \\
\hline Pengharum Ruangan harian & 4 & 4 & 5 \\
\hline Pemutih Baju Botol & 2 & 4 & 4 \\
\hline Pemutih Baju Sachet & 3 & 4 & 3 \\
\hline Pewarna Rambut & 4 & 3 & 3 \\
\hline Pengharum Ruangan All IN One & 3 & 4 & 1 \\
\hline Tisu Basah Pocket & 4 & 4 & 4 \\
\hline Obat Nyamuk One Push & 3 & 4 & 4 \\
\hline
\end{tabular}

\subsection{Penentuan pemetaan selisih atau gap}

Pada tahapan ini setiap produk akan memiliki tabel bobot nilai sesuai dengan tabel bobot nilai gap (Tabel 5) dengan aspek kategori promosi produk yaitu budget (B), penjualan (P), dan waktu (W). Untuk core factor sesuai dengan kategori promosi produk yang sering ditawarkan oleh distributor kepada minimarket adalah budget dan penjualan, sementara untuk secondary factor adalah waktu promosi seperti terlihat pada tabel 6 .

Tabel 5. Keterangan Bobot nilai Gap

\begin{tabular}{|cccl|}
\hline No & Selisih & $\begin{array}{c}\text { Bobot } \\
\text { Nilai }\end{array}$ & \multicolumn{1}{c|}{ Keterangan } \\
\hline 1 & 0 & 5 & $\begin{array}{l}\text { Tidak ada selisih } \\
\text { (kompetensi sesuai dengan } \\
\text { kebutuhan) }\end{array}$ \\
\hline 2 & -1 & 4.5 & $\begin{array}{l}\text { Kompetensi individu } \\
\text { kelebihan 1 level }\end{array}$ \\
\hline 3 & 1 & 4 & $\begin{array}{l}\text { Kompetensi individu } \\
\text { kekurangan 1 level }\end{array}$ \\
\hline 4 & -2 & 3.5 & $\begin{array}{l}\text { Kompetensi individu } \\
\text { kelebihan 2 level }\end{array}$ \\
\hline 5 & 2 & 3 & $\begin{array}{l}\text { Kompetensi individu } \\
\text { kekurangan 2 level }\end{array}$ \\
\hline 6 & -3 & 2.5 & $\begin{array}{l}\text { Kompetensi individu } \\
\text { kelebihan 3 level }\end{array}$ \\
\hline 7 & 3 & 2 & $\begin{array}{l}\text { Kompetensi individu } \\
\text { kekurangan 3 level }\end{array}$ \\
\hline
\end{tabular}

\begin{tabular}{|cccl|}
\hline 8 & -4 & 1.5 & $\begin{array}{l}\text { Kompetensi individu } \\
\text { kelebihan 4 level }\end{array}$ \\
\hline 9 & 4 & 1 & $\begin{array}{l}\text { Kompetensi individu } \\
\text { kekurangan 4 level }\end{array}$ \\
\hline
\end{tabular}

Tabel 6. Hasil Pemetaan Bobot Nilai Gap

\begin{tabular}{|c|c|c|c|}
\hline Nama Produk & $\mathbf{B}$ & $\mathbf{P}$ & $\mathbf{W}$ \\
\hline Pengharum Ruangan Semprot & -1 & -2 & -1 \\
\hline $\begin{array}{l}\text { Pengharum Ruangan Kamar } \\
\text { Mandi }\end{array}$ & 0 & -2 & -1 \\
\hline $\begin{array}{l}\text { Pengharum Ruangan ALL in } \\
\text { One }\end{array}$ & -2 & 0 & 0 \\
\hline Obat Nyamuk Semprot & 0 & 0 & -1 \\
\hline Obat Nyamuk Non Stop & -1 & -3 & 0 \\
\hline Obat Nyamuk Anti Kecoa & 0 & 0 & 0 \\
\hline Tisu Basah Baby & -1 & -1 & -2 \\
\hline Tisu Basah Anti Septic & -2 & 0 & 0 \\
\hline Tisu Basah Reguler & 0 & -3 & -3 \\
\hline Pengharum Mobil Anti Bakteri & 0 & -1 & 0 \\
\hline Pengharum Ruangan harian & 0 & 0 & 0 \\
\hline Pemutih Baju Botol & -2 & 0 & -1 \\
\hline Pemutih Baju Sachet & -1 & 0 & -2 \\
\hline Pewarna Rambut & 0 & -1 & -2 \\
\hline Pengharum Ruangan All IN One & -1 & 0 & -4 \\
\hline Tisu Basah Pocket & 0 & 0 & -1 \\
\hline Obat Nyamuk One Push & -1 & 0 & -1 \\
\hline \multicolumn{4}{|l|}{ Keterangan Bobot GAP } \\
\hline Nama Produk & B & $\mathbf{W}$ & $\mathbf{P}$ \\
\hline Pengharum ruangan Semprot & 3 & 4 & 2 \\
\hline $\begin{array}{l}\text { Pengharum ruangan Kamar } \\
\text { Mandi }\end{array}$ & 4 & 4 & 2 \\
\hline $\begin{array}{l}\text { Pengharum Ruangan ALL in } \\
\text { One }\end{array}$ & 2 & 5 & 4 \\
\hline Obat Nyamuk Semprot & 4 & 4 & 4 \\
\hline Obat Nyamuk Non Stop & 3 & 5 & 1 \\
\hline Obat Nyamuk Anti Kecoa & 4 & 5 & 4 \\
\hline Tisu Basah Baby & 3 & 3 & 3 \\
\hline Tisu Basah Anti Septic & 2 & 5 & 4 \\
\hline Tisu Basah Reguler & 4 & 2 & 1 \\
\hline Pengharum Mobil Anti Bakteri & 4 & 5 & 3 \\
\hline Pengharum Ruangan harian & 4 & 5 & 4 \\
\hline Pemutih Baju Botol & 2 & 4 & 4 \\
\hline Pemutih Baju Sachet & 3 & 3 & 4 \\
\hline Pewarna Rambut & 4 & 3 & 3 \\
\hline Pengharum Ruangan All IN One & 3 & 1 & 4 \\
\hline Tisu Basah Pocket & 4 & 4 & 4 \\
\hline Obat Nyamuk One Push & 3 & 4 & 4 \\
\hline
\end{tabular}




\subsection{Menghitung NCF dan NSF}

Selanjutnya dilakukan perhitungan dan pengelompokan core dan secondary factor dengan hasil seperti terlihat pada Tabel 7.

Tabel 7. Hasil Pemetaan Bobot Nilai Gap

\begin{tabular}{|lccccc|}
\hline Nama Produk & $\mathrm{B}$ & $\mathrm{P}$ & $\mathrm{W}$ & $\mathrm{NCF}$ & $\mathrm{NSF}$ \\
\cline { 1 - 4 } $\begin{array}{l}\text { Pengharum } \\
\text { Ruangan } \\
\text { Semprot }\end{array}$ & -1 & -2 & -1 & 2,5 & 2 \\
\hline $\begin{array}{l}\text { Pengharum } \\
\text { Ruangan Kamar } \\
\text { Mandi }\end{array}$ & 0 & -2 & -1 & 3 & 2 \\
\hline $\begin{array}{l}\text { Pengharum } \\
\text { Ruangan ALL } \\
\text { in One }\end{array}$ & -2 & 0 & 0 & 3 & 2,5 \\
\hline $\begin{array}{l}\text { Obat Nyamuk } \\
\text { Semprot }\end{array}$ & 0 & 0 & -1 & 4 & 2 \\
\hline $\begin{array}{l}\text { Obat Nyamuk } \\
\text { Non Stop }\end{array}$ & -1 & -3 & 0 & 2 & 2,5 \\
\hline $\begin{array}{l}\text { Obat Nyamuk } \\
\text { Anti Kecoa }\end{array}$ & 0 & 0 & 0 & 4 & 2,5 \\
\hline $\begin{array}{l}\text { Tisu Basah } \\
\text { Baby }\end{array}$ & -1 & -1 & -2 & 3 & 1,5 \\
\hline $\begin{array}{l}\text { Tisu Basah Anti } \\
\text { Septic }\end{array}$ & -2 & 0 & 0 & 3 & 2,5 \\
\hline $\begin{array}{l}\text { Tisu Basah } \\
\text { Reguler }\end{array}$ & 0 & -3 & -3 & 2,5 & 1 \\
\hline $\begin{array}{l}\text { Pengharum } \\
\text { Mobil Anti } \\
\text { Bakteri }\end{array}$ & 0 & -1 & 0 & 3,5 & 2,5 \\
\hline $\begin{array}{l}\text { Pengharum } \\
\text { Ruangan harian }\end{array}$ & 0 & 0 & 0 & 4 & 2,5 \\
\hline $\begin{array}{l}\text { Pemutih Baju } \\
\text { Botol }\end{array}$ & -2 & 0 & -1 & 3 & 2 \\
\hline $\begin{array}{l}\text { Pemutih Baju } \\
\text { Sachet }\end{array}$ & -1 & 0 & -2 & 3,5 & 1,5 \\
\hline $\begin{array}{l}\text { Pewarna } \\
\text { Rambut }\end{array}$ & 0 & -1 & -2 & 3,5 & 1,5 \\
\hline $\begin{array}{l}\text { Pengharum } \\
\text { Ruangan All IN } \\
\text { One }\end{array}$ & -1 & 0 & -4 & 3 & 2,5 \\
\hline $\begin{array}{l}\text { Tisu Basah } \\
\text { Pocket }\end{array}$ & 0 & 0 & -1 & 4 & 2 \\
\hline $\begin{array}{l}\text { Obat Nyamuk } \\
\text { One Push }\end{array}$ & -1 & 0 & -1 & 3,5 & 2 \\
\hline
\end{tabular}

Selanjutnya dilakukan perhitungan untuk total core factor dengan menghitung rata-rata dari bobot nilai gap dari core factor dan membandingkan dengan secondary factor dengan perbandingan $70 \%$ untuk core factor dan $30 \%$ untuk secondary factor. Seperti terlihat pada Tabel 8.
Tabel 8. Perhitungan Nilai Total

\begin{tabular}{|c|c|c|c|c|c|c|}
\hline $\begin{array}{c}\text { Nama } \\
\text { Produk }\end{array}$ & B & $\mathrm{P}$ & W & NCF & NSF & NI \\
\hline $\begin{array}{l}\text { Pengharum } \\
\text { Ruangan } \\
\text { Semprot }\end{array}$ & -1 & -2 & -1 & 2,5 & 2 & 2,33 \\
\hline $\begin{array}{l}\text { Pengharum } \\
\text { Ruangan } \\
\text { Kamar } \\
\text { Mandi }\end{array}$ & 0 & -2 & -1 & 3 & 2 & 2,67 \\
\hline $\begin{array}{l}\text { Pengharum } \\
\text { Ruangan } \\
\text { ALL in One }\end{array}$ & -2 & 0 & 0 & 3 & 2,5 & 2,83 \\
\hline $\begin{array}{l}\text { Obat } \\
\text { Nyamuk } \\
\text { Semprot }\end{array}$ & 0 & 0 & -1 & 4 & 2 & 3,33 \\
\hline $\begin{array}{l}\text { Obat } \\
\text { Nyamuk } \\
\text { Non Stop }\end{array}$ & -1 & -3 & 0 & 2 & 2,5 & 2,17 \\
\hline $\begin{array}{l}\text { Obat } \\
\text { Nyamuk } \\
\text { Anti Kecoa }\end{array}$ & 0 & 0 & 0 & 4 & 2,5 & 3,5 \\
\hline $\begin{array}{l}\text { Tisu Basah } \\
\text { Baby }\end{array}$ & -1 & -1 & -2 & 3 & 1,5 & 2,5 \\
\hline $\begin{array}{l}\text { Tisu Basah } \\
\text { Anti Septic }\end{array}$ & -2 & 0 & 0 & 3 & 2,5 & 2,83 \\
\hline $\begin{array}{l}\text { Tisu Basah } \\
\text { Reguler }\end{array}$ & 0 & -3 & -3 & 2,5 & 1 & 2 \\
\hline $\begin{array}{l}\text { Pengharum } \\
\text { Mobil Anti } \\
\text { Bakteri }\end{array}$ & 0 & -1 & 0 & 3,5 & 2,5 & 3,17 \\
\hline $\begin{array}{l}\text { Pengharum } \\
\text { Ruangan } \\
\text { harian }\end{array}$ & 0 & 0 & 0 & 4 & 2,5 & 3,5 \\
\hline $\begin{array}{l}\text { Pemutih } \\
\text { Baju Botol }\end{array}$ & -2 & 0 & -1 & 3 & 2 & 2,67 \\
\hline $\begin{array}{l}\text { Pemutih } \\
\text { Baju Sachet }\end{array}$ & -1 & 0 & -2 & 3,5 & 1,5 & 2,83 \\
\hline $\begin{array}{l}\text { Pewarna } \\
\text { Rambut }\end{array}$ & 0 & -1 & -2 & 3,5 & 1,5 & 2,83 \\
\hline $\begin{array}{l}\text { Pengharum } \\
\text { Ruangan All } \\
\text { IN One }\end{array}$ & -1 & 0 & -4 & 3 & 2,5 & 2,83 \\
\hline $\begin{array}{l}\text { Tisu Basah } \\
\text { Pocket }\end{array}$ & 0 & 0 & -1 & 4 & 2 & 3,33 \\
\hline $\begin{array}{l}\text { Obat } \\
\text { Nyamuk One } \\
\text { Push }\end{array}$ & -1 & 0 & -1 & 3,5 & 2 & 3 \\
\hline
\end{tabular}

\subsection{Hasil Rekomendasi}

Langkah terakhir adalah membuat berdasarkan range nilai keterangan seperti terlihat pada Tabel 9. 
Tabel 9. Tabel Keterangan

\begin{tabular}{|cll|}
\hline No & $\begin{array}{r}\text { Kriteria } \\
\text { Promosi }\end{array}$ & \multicolumn{1}{c|}{ Range Nilai } \\
\hline 1 & Rafaksi & $\geq 3.00$ \\
\hline 2 & Mailer & $<3.00$ and $\geq 2.50$ \\
\hline 3 & Discount & $\geq 1.50$ and $<2.50$ \\
\hline 4 & Listing & $<1.50$ \\
\hline
\end{tabular}

Berdasarkan tabel keterangan (Tabel 9) menunjukkan bahwa:

a. Promosi Rafaksi

Merupakan pemotongan atau pengurangan terhadap harga barang karena adanya akitivitas promosi di outlet tertentu, biasa promosi rafkasi dilakukan masimal hanya 7 hari. Menghasilkan rekomendasi promosi rafaksi pada produk jika Nilai lebih besar atau sama dengan 3.00

b. Promosi Mailer

Merupakan pemotongan atau pengurangan terhadap harga melalui leaflet berupa katalog atau lainnya. Menghasilkan rekomendasi promosi mailer pada produk jika nilai lebih kecil dari 3.00 dan lebih besar sama dengan 2.50

c. Promosi Discount

Merupakan pemotongan atau pengurangan terhadap harga barang berdasarkan kebijakan dari supplier. Menghasilkan rekomendasi promosi discount pada produk jika nilai lebih besar sama dengan 1.50 dan lebih kecil dari 2.50

d. Promosi Listing

Merupakan pemotongan atau pengurangan terhadap harga barang untuk kebutuhan promo yang berkaitan dengan peluncuran produk baru. Menghasilkan rekomendasi promosi listing pada produk jika nilai lebih kecil dari 1.50 
Tabel 10. Tabel Rekomedasi Promosi

\begin{tabular}{|lccccl|}
\hline \multirow{2}{*}{ Nama Produk } & \multicolumn{3}{c}{ Hasil } & \multirow{2}{*}{ Rekomendasi } \\
\cline { 2 - 4 } & NCF & NSF & NI & & \\
\hline Pengharum ruangan Semprot & 2,5 & 2 & 2,33 & 3 & Discount \\
\hline Pengharum ruangan Kamar Mandi & 3 & 2 & 2,67 & 2 & Mailer \\
\hline Pengharum Ruangan ALL in One & 3 & 2,5 & 2,83 & 2 & Mailer \\
\hline Obat Nyamuk Semprot & 4 & 2 & 3,33 & 1 & Rafaksi \\
\hline Obat Nyamuk Non Stop & 2 & 2,5 & 2,17 & 3 & Discount \\
\hline Obat Nyamuk Anti Kecoa & 4 & 2,5 & 3,50 & 1 & Rafaksi \\
\hline Tisu Basah Baby & 3 & 1,5 & 2,50 & 3 & Mailer \\
\hline Tisu Basah Anti Septic & 3 & 2,5 & 2,83 & 2 & Mailer \\
\hline Tisu Basah Reguler & 2,5 & 1 & 2,00 & 3 & Discount \\
\hline Pengharum Mobil Anti Bakteri & 3,5 & 2,5 & 3,17 & 1 & Rafaksi \\
\hline Pengharum Ruangan harian & 4 & 2,5 & 3,50 & 1 & Rafaksi \\
\hline Pemutih Baju Botol & 3 & 2 & 2,67 & 2 & Mailer \\
\hline Pemutih Baju Sachet & 3,5 & 1,5 & 2,83 & 2 & Mailer \\
\hline Pewarna Rambut & 3,5 & 1,5 & 2,83 & 2 & Mailer \\
\hline Pengharum Ruangan All IN One & 3,5 & 0,5 & 2,50 & 3 & Mailer \\
\hline Tisu Basah Pocket & 4 & 2 & 3,33 & 1 & Rafaksi \\
\hline Obat Nyamuk One Push & 3,5 & 2 & 3,00 & 2 & Mailer \\
\hline
\end{tabular}

Berdasarkan tabel keterangan (Tabel 9), maka akan menghasilkan rekomendasi untuk kategori promosi pada setiap produk (Tabel 10).

\section{SIMPULAN DAN SARAN}

Kesimpulan yang dapat penulis ambil setelah melakukan penelitian ini adalah:

1. Pengambilan keputusan kategori promosi produk dilakukan dengan melihat tiga aspek yaitu budget, penjualan dan waktu promosi.

2. Penerapan metode profile matching untuk pengambilan keputusan kategori promosi produk dilakukan dengan pemberian bobot terhadap aspek yang telah ditentukan, perhitungan nilai core factor (NCF) dan nilai secondary factor (NSF), perhitungan nilai total dan rekomendasi hasil.

3. Pengambilan keputusan kategori promosi produk dengan metode profile matching dapat membantu perusahaan distributor dalam menentukan promo untuk setiap produk yang dimiliki
Penulis mengharapkan pengembangan lebih lanjut dari sistem pendukung keputusan keputusan kategori promosi produk dengan metode profile matching ini sehingga memberikan beberapa saran yaitu :

1.Penerapan pendukung keputusan pemilihan kategori promosi produk dengan metode profile matching menggunakan aplikasi komputer sehingga pengolahan data dapat dilakukan dengan lebih cepat dan akurat.

2.Aplikasi Komputer yang digunakan perlu didukung perangkat yang memadai baik dari software maupun hardware yang digunakan

3.Untuk penggunaan aplikasi Komputer pendukung keputusan pemilihan kategori promosi produk dengan metode profile matching ini sebaiknya pemakai aplikasi diberikan latihan terlebih dahulu 


\section{UCAPAN TERIMA KASIH}

Terimakasih kepada semua pihak yang telah membantu saya dalam menyelesaikan penelitian ini yang tidak bisa saya sebutkan satu persatu, terimakasih juga kepada LPPM Universitas Bumigora Mataram dan seluruh Redaksi Matrik yang mememberikan saya kesempatan untuk menerbitkan tulisan di Jurnal Matrik.

\section{REFERENSI}

[1] Kusrini, Konsep dan Aplikasi Sistem Penunjang Keputusan, Yogyakarta: Andi Offset, 2007.

[2] S. Sianturi, "Sistem Pendukung Keputusan Penentuan Kebijakan Strategi Promosi Kampus Dengan Metode Profile Matching," Pelita Informatika Budi Darma, vol. IX, no. 2, pp. $60-68,2015$.

[3] R. . K. Tiony, N. H. Wardani dan T. Afirianto, "Sistem Pendukung Keputusan Pemilihan Produk Promo Dengan Menggunakan Metode Analytical Hierarchy Process - Simple Additive Weighting (AHP SAW) (Studi Kasus : Geprek Kak Rose)," Pengembangan Teknologi Informasi dan Ilmu Komputer, vol. 3, no. 9, pp. 8413-8422, 2019.

[4] F. Indriyani, "Penerapan Metode Profile matching Sebagai Pendukung Keputusan Pemilihan Jurusan pada SMK Al Hidayah," Jurnal Riset Informatika, vol. 1, no. 2, p. 35 40, 2019.

[5] Kusrini, Konsep dan Aplikasi Sistem Pendukung Keputusan, Yogyakarta: Andi + AMIKOM, 2017.

[6] A. Yasiin dan . K. P. Desi , "Sistem Pendukung Keputusan Penerimaan Siswa Baru menggunakan Metode Profil Matching pada SMK Wisudha Karya Kudus,” 2017. 